\title{
EFFECTS OF INTRAVENOUS INFUSION OF GENTRAL DEPRESSANTS ON THE EVOKED POTENTIALS OF THE AUDITORY CORTEX IN THE CATS
}

\author{
YOSHIHISA NAKAI \\ Department of Oto-Rhino-Laryngology and Department of Pharmacology, \\ Faculty of Medicine, Kyoto University, Sakyo-ku, Kyoto \\ Received for publication February 7, 1964
}

Effort toward finding some integrative functions in the cortical projection areas of the auditory systems has been made by several investigators. Raab and Ades (1) have reported that temporary amnesia for the learned habit is founded after bilateral ablation of the auditory cortcx, but the habit is readily relearned. On the other hand, Neff et al. (2) have demonstrated that bilateral ablation of auditory cortex in the cat does lead to a lasting deficit in ability to localize sound in space. They have suggested following hypotheses: 1) an intact auditory cortex is necessary in order that the relationship between auditory signal and food reward may be learned, 2) an intact auditory cortex is essentially for maintenance to attention to an auditory signal, and 3) an intact auditory cortex is necessary for accurate localization of sound in space. However, the results have failed clearly to single out any of these. Lilly (3) and Lilly and Chcrry (4) have shown the patterns of spontaneous electrical activity and those evoked by acoustic stimulation in the auditory cortex of the cat by means of a recording technique which gives simultaneous samples of the electrical activity from 25 electrodes on the cercbral cortex. From the observations under light and deep anesthesia, they have demonstrated that there is a ccrtain validity to the accepted subdivision of auditory cortex, although this may have been overplayed in the past because most workers have used deeply anesthctized animals as the standard preparation.

Effects of anesthetics on the spontancous activity and the evoked rcsponses in the auditory cortex have also been shown by Reinberger and Jasper (5), Brazier (6), Kiang et al. (7) and Pradhan and Galambos (8). It is generally known that most of anesthetics or hypnotics produce behavioral excitement in the induction phase. However, there is scarcely any systematic study for the relationship between the cerebral acoustic activity and infuscd doses of the anesthetics. The present experiments were designed to observe the effects of the central depressants continuously and intravenously infused on the spontaneous clectrical activity and the response of the auditory cortex to acoustic stimuli in order to analyze the cortical or subcortical mechanism of hearing. 


\section{METHODS}

Seventy adult cats, weighing $2.0 \mathrm{to} 3.5 \mathrm{~kg}$ and of either scx, were used. The cxperiments werc performed in a dark and semi-sound-proof room at the temperature of 25 to $30^{\circ} \mathrm{C}$.

Operative procedures: Fixation of the cat and succecding operative procedure were performed under ether anesthesia. After an insertion of the tracheal cannula the left auditory cortex such as anterior, middle and posterior ectosylvian gyri (AEG, MEG and PEG) and anterior and middle suprasylvian gyri (ASG and MSG) were exposed as widely as possible by resecting the temporal cranial muscles and skull. Attention was taken to prevent hemorrhage and not to compress the dura mater. Then, unless otherwise stated, the spinal cord was sectioned at the level of $\mathrm{C}_{1}$ (encéphale isolé preparation). Immediatcly thereafter, the animal was fixed on a stereotaxic instrument of TodaiNoken type and was maintained by artificial respiration. The head of animal was immobilized with the modified bars fixed in the mandibular bone bilaterally instcad of insertion of bars into the extcrnal meatus of the ears.

Electrodes: Evoked potentials were recorded with the tip of a small silver wire which acted as a monopolar electrode. The indifferent electrode was placed on the frontal cranial bone.

Acoustic stimuli: The animals were stimulated with the binaural clicks produced by the activation of earphone with $0.1 \mathrm{msec}$ rectangular pulse delivered from a electronic stimulator of Nihon-Koden Co. type. The earphone was placed at the location $20 \mathrm{~cm}$ vertically apart from the middle of the head of animal. The click stimuli were repeated at five seconds intervals. The sound level was adjusted to obtain a maximal amplitude of the evoked potential.

Amplifications: For amplification of the evoked potential preamplifiers and direct current amplificrs of Sanci-Sokki Co. typc werc used. The potential thus amplified was transmitted to a cathode ray oscilloscope or ink-writing recorder.

Recordings: The evoked potentials were photographed by use of the camera from the cathode ray oscilloscope. The mean amplitude of the potentials was calculated by measuring ten potentials recorded every two stimulation. Simultaneously with the photographing of the evoked potentials the spontaneous electrical activity of the auditory cortex was traced by means of the ink-writing oscillograph.

Administration of drugs: The drugs uscd in the present experiments were pentobarbital sodium, chloralose, ethylalcohol, chlorpromazinc hydrochloride, urethane, morphine hydrochloride, methamphetamine hydrochloride and strychnine nitrate. Each drug was dissolved in Ringer's solution in the various concentrations except chlorpromazine which was dissolved in physiological saline solution. The drug solution was injected into the ulnar vein at the speed of $100 \mathrm{ml} /$ hour. The anesthetic effects were contrasted to the amount of drug injected at least every five minutes. 


\section{RESULTS}

1. Evoked polentials on the auditory cortex in response to click stimuli in the unanesthetized cats (encéphale isolé preparation)

The cortical evoked potentials in the encéphale isolé preparations of the cats showed the following characteristics. The evoked potentials were observed in the relatively restricted areas of the auditory cortex. Fig. 1 shows the distribution of the cvoked

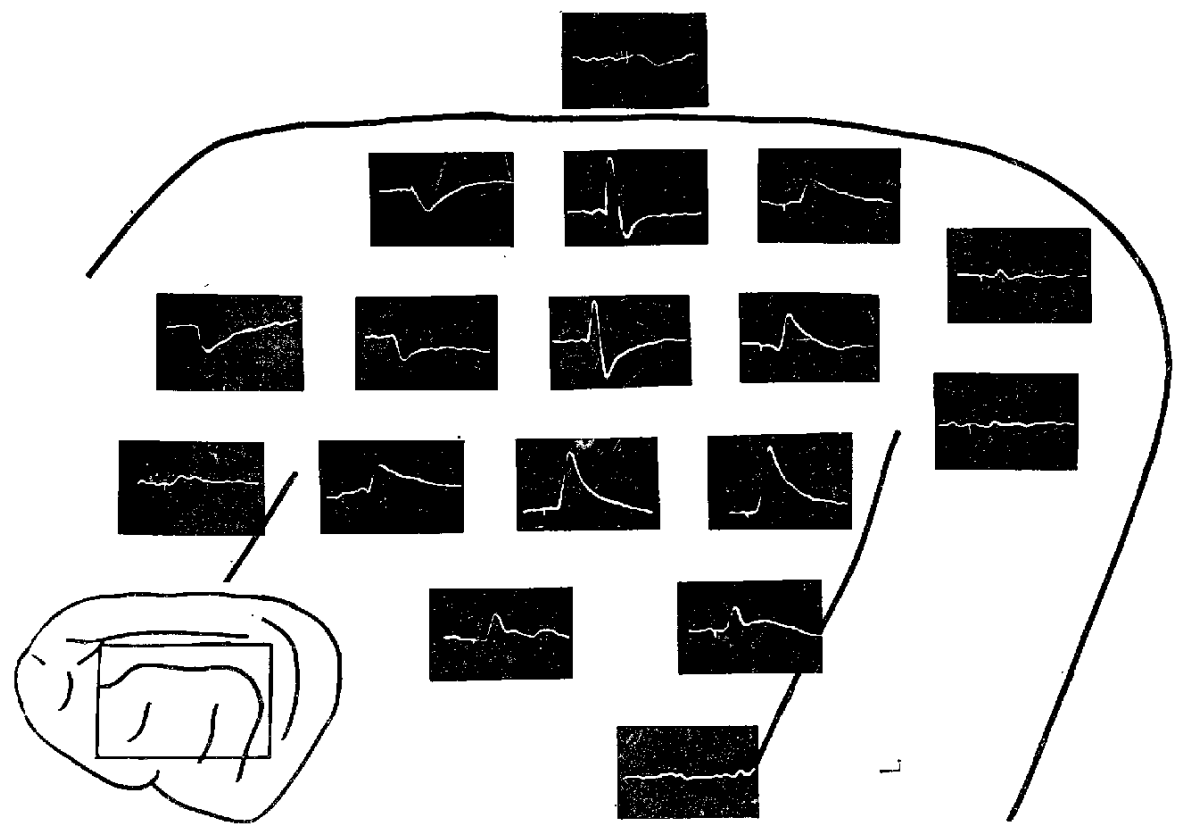

FIG. 1. Cortical map of evoked potentials on the left cerebral cortex of unanesthetized cat in response to binaural click stimuli.

Calibration : ordinate $10 \mu \mathrm{V}$, abscissa $20 \mathrm{msec}$.

potentials in the left cerebral cortex in response to the binaural click stimuli. Though the auditory evoked potentials were usually observed in the middle cctosylvian gyrus (MEG), a typical potential with a large amplitude was recorded in the central part of the middle ectosylvian gyrus (MEG). The auditory evoked potential observed in the ccntral part of MEG consisted of typical triphasic waves, the initial negative wave followed by a large positive wave and further by a slow negative wave. Upper defrections show the positive components. The deviation of the recording site from there markedly dccreased the amplitude and modified to the response irregular. Therefore, the evoked potentials recorded in the vicinity of the anterior ectosylvian gyrus (AEG) showed only a negative wave and those recorded in the posterior ectosylvian gyrus (PEG) were small positive waves. The potential failed to record in anterior and middle suprasylvian gyri (ASG and MSG) even if the supramaximal stimuli were applied. An amplitude of typical potential in the auditory cortex in response to maximal click stimuli was about 200 to $1,000 \mu \mathrm{V}$ and a duration about 40 to $50 \mathrm{msec}$. The configuration of 
the evoked potential was easily and sensitively affected by the change of the cnvironmental condition. Especially, the patterns of wave and amplitude werc so unstable that they were easily depressed by projection of noise or light. Otherwise, the acoustic stimulation with the consecutive clicks applied at the interval of 1 to 2 seconds induced the reproducible responses without decrease in amplitude and duration of the evoked potentials. However, the reduction of the interval to $1 / 8$ to $1 / 4$ second decreased the amplitude of the potentials significantly. Since fairly constant configuration of the evoked potential was repeatedly obtained by the maximal or supramaximal stimuli at the interval of 5 seconds, the effects of the central depressants werc observed on a maximal response in the central part of MEG. The configuration of the acoustic evoked potential induce from the corresponding area of the left or right cortex did not show any significant variation.

II. EEG on the auditory and motor cortices in response to click stimuli

The EEGs recorded from the motor cortex, AEG, MEG and PEG in the auditory cortex of the unanesthetizcd cat (encéphale isolé preparations) wcre shown in Fig. 2. The

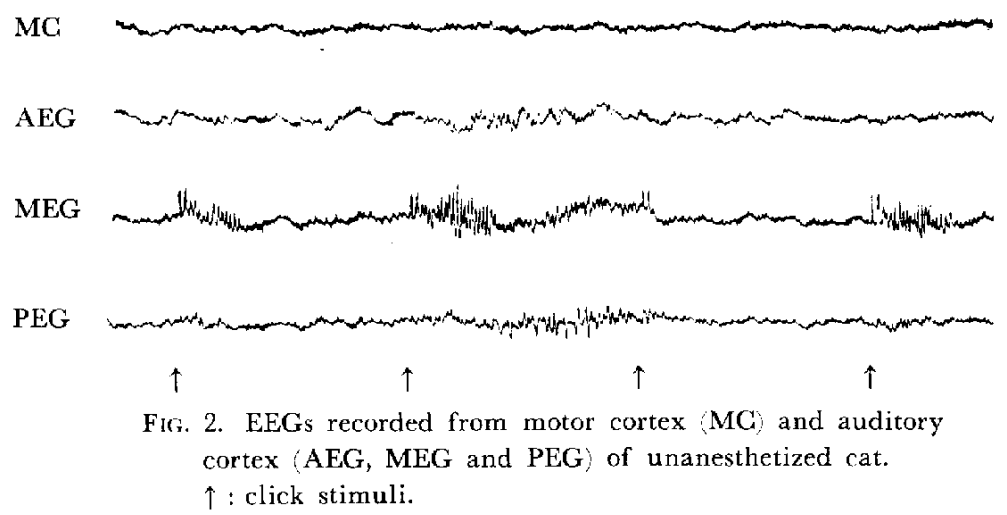

spontaneous electrical activity recorded from the auditory cortex showed fundamentally low voltage fast wave (20 to $60 \mu \mathrm{V}$ in amplitude and 30 to $35 \mathrm{cps}$ in frequency). In some of the animals EEG showed slightly slower pattern of waves (15 to $20 \mathrm{cps}$ ) intermingled sometimes with the spindle bursts.

The manifestation of the auditory evoked potential, 200 to $1,000 \mu \mathrm{V}$ in amplitude, in response to maximal stimuli was followed by the evoked rhythmic after-discharge, 10 to $15 \mathrm{cps}$ in frequency, 200 to $300 \mu \mathrm{V}$ in amplitude, and lasting for 1 to 1.5 seconds. However, the activation of the spontaneous EEG by click stimuli was not always obscrved in the unanesthctized animals. It was less complete in some animals or it lacked in some others. The simultaneous recording of EEGs in the motor and auditory cortices showed that the evoked rhythmic after-discharge was not observed in the EEG of the motor cortex, but the spindle bursts manifested synchronously in the EEGs of the motor and auditory cortices. However, the evoked rhythmic after-discharge was not observed during the manifestation of the spindle bursts even if the click stimuli wore applied. In 
addition, the cvoked rhythmic after-discharge could not be seen when the click stimuli were applied immediately after the disappearance of the spindle bursts.

III. Effects of the intravenous infusion of central depressants

7. Effects of Ringer's solution

The change of the amplitude of the auditory evoked potentials was observed in the unanesthctized cat during the continuous intravenous infusion of warmed $(37 \mathrm{C})$ Ringer's solution at the rate of $100 \mathrm{ml} /$ hour. The change of the amplitude was within the range of $\pm 20 \%$ which was also observed in the preparation with the treatment of Ringer's solution, however, the incrcase or decrease of the amplitude did not show a steady tendency. The duration of the potentials was not changed.

\section{Effects of pentobarbital sodium}

The effects of the full anesthetization of the intact animal on the auditory cortical response wcre studied in the cats which was injected intraperitoneally $50 \mathrm{mg} / \mathrm{kg}$ of pentobarbital sodium. The evoked potentials were readily recorded from the diffuse areas of the auditory cortex, AEG, PEG, ASG, MSG and especially MEG. It was not recorded from other areas of cortex. Though the configuration of the potentials was considerably stable within prcparation, it subjected to variation such as mono-, bi- and triphasic waves betwecn preparations. However, the typical potentials consisted of triphasic waves similarly to that in the unancsthetizcd preparation. The latcncy for the manifcstation of the responsc was usually 9 to $10 \mathrm{msec}$ and the duration was 20 to $30 \mathrm{msec}$. The maximal amplitude $(50$ to $200 \mu \mathrm{V}$ ) of the response was recorded on the central part of the MEG, though the deviation of the recording site from there decreased gradually the amplitude and modified to the response irregular.

'The time course of the change of the spontaneous electrical activity and the evoked potcntials in the auditory cortex was studied in the encéphale isolé prcparation during the continuous infusion of $20 \mathrm{mg} / \mathrm{kg}$ of pentobarbital sodium dissolved in $100 \mathrm{ml}$ of Ringer's solution per one hour. Fig. 3 shows the relationship between the changes of amplitude

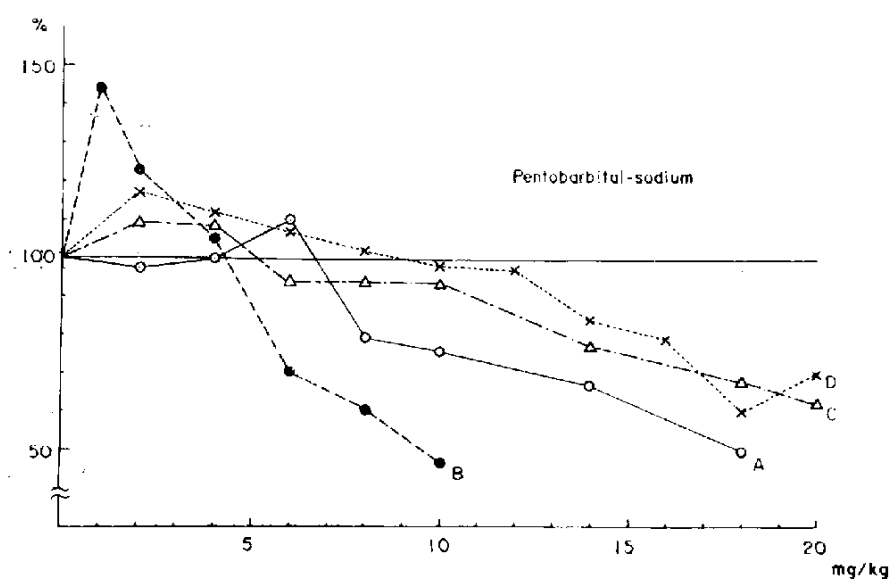

Fic. 3. Relationship between per cent changes of amplitude of the auditory croked potentials and infused doses of pentobarbital sodium in four preparations. 
of the evoked potentials and the injected doses in four preparations. Each point represents the mean value of ten measured height of amplitude express as per cent change of that the start of the infusion. Immediately after the commencement of the infusion the amplitude of the potentials showed a steady tendency to increase until the total infused dose amounted to about $5 \mathrm{mg} / \mathrm{kg}$. The increase in the amplitude at the total dose of 2 to $5 \mathrm{mg} / \mathrm{kg}$ was about 10 to $40 \%$. The further infusion of the drug decreased the amplitude slowly but progressively. The decrease was 10 to $20 \%$ at the total dose of 10 $\mathrm{mg} / \mathrm{kg}$ and 30 to $50 \%$ at $20 \mathrm{mg} / \mathrm{kg}$.

Typical change of the auditory evoked potentials in response to the infusion of pentobarbital sodium in one of the preparations is illustrated in Fig. 4. The latency of response was not markcdly affected at any doses of the drugs. On the other hand, increase of the dose caused marked decrease of the duration of the potential. The duration of the potentials $(50 \mathrm{mscc}$ beforc the start of the infusion) decreased to $40 \mathrm{msec}$ at the dose of $4 \mathrm{mg} / \mathrm{kg}$, $30 \mathrm{msec}$ at that of $8 \mathrm{mg} / \mathrm{kg}$ and $20 \mathrm{msec}$ at that of $20 \mathrm{mg} / \mathrm{kg}$.

The effects of the intravenous infusion of pentobarbital sodium on the EEG recorded from the MEG are shown in Fig. 5. The background arousal patterns of the consisted of low voltage fast wave and manifested incompletely evoked rhythmic after-discharge, 10 to $15 \mathrm{cps}$ in frequency, 100 to $200 \mu \mathrm{V}$ in amplitude and 1.5 seconds in duration, in response to the repetition of the click stimuli. At the dose levels of 2 to $4 \mathrm{mg} / \mathrm{kg}$ of the drug the evoked rhythmic after-discharge responded to every repetition of the stimulation. However, the background activity of the EEG turned to the slow waves at the total dose of $6 \mathrm{mg} / \mathrm{kg}$ of pentobarbital sodium and the evoked rhythmic after-discharge manifestcd irregularly. However, the duration of the rhythmic after-discharge was prolonged to 2 to 2.5 seconds and the amplitude of the discharge increased significantly. At the total dose of $10 \mathrm{mg} / \mathrm{kg}$ the frequency of the rhythmic after-discharge reduced to 8 to $10 \mathrm{cps}$. The further increase of the 
1

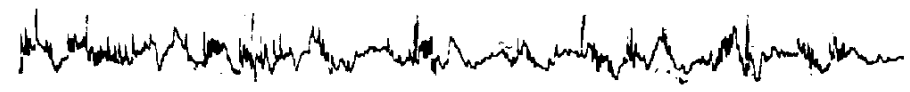

2

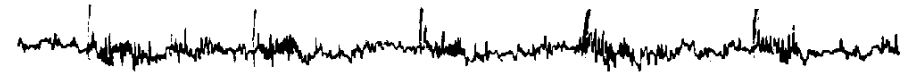

3

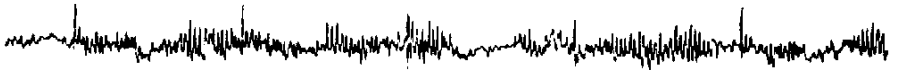

4

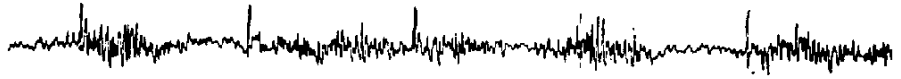

5

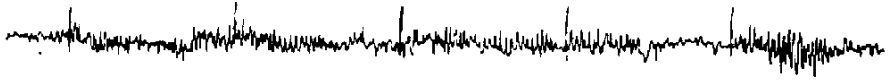

6

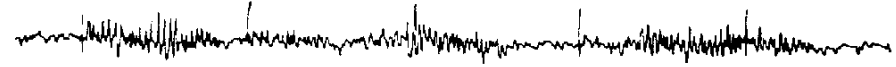

7

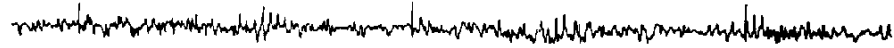

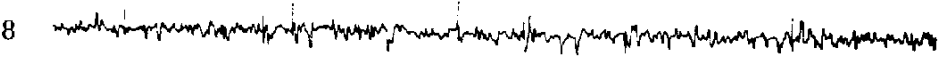

FIG. 5. Effects of infusion of pentobarbital sodium on EEG recorded from MEG. (1) Before, (2) $4 \mathrm{mg} / \mathrm{kg}$, (3) $6 \mathrm{mg} / \mathrm{kg}$, (4) $8 \mathrm{mg} / \mathrm{kg}$, (5) $10 \mathrm{mg} / \mathrm{kg},(6) 14 \mathrm{mg} / \mathrm{kg}$, (7) $18 \mathrm{mg} / \mathrm{kg}$ and 8 , $20 \mathrm{mg} / \mathrm{kg}$.

Calibration : ordinate $100 \mu \mathrm{V}$, abscissa 1 sec.

total dose resulted in the further slowing of the EEG and at last in the complete disappearance of the after-discharge. After the termination of the infusion the recovery of the evoked potential to about $80 \%$ of the amplitude before the infusion was observed only in one preparation. In the other three preparations the depression progressed further.

\section{Effects of chloralose}

Chloralose in the dose of $100 \mathrm{mg} / \mathrm{kg}$ dissolved in $100 \mathrm{ml}$ of Ringer's solution was infused intravenously per onc hour. Immediately after the commencement of the infusion the amplitude of the evoked potentials turned to an increase and the peak effect of 


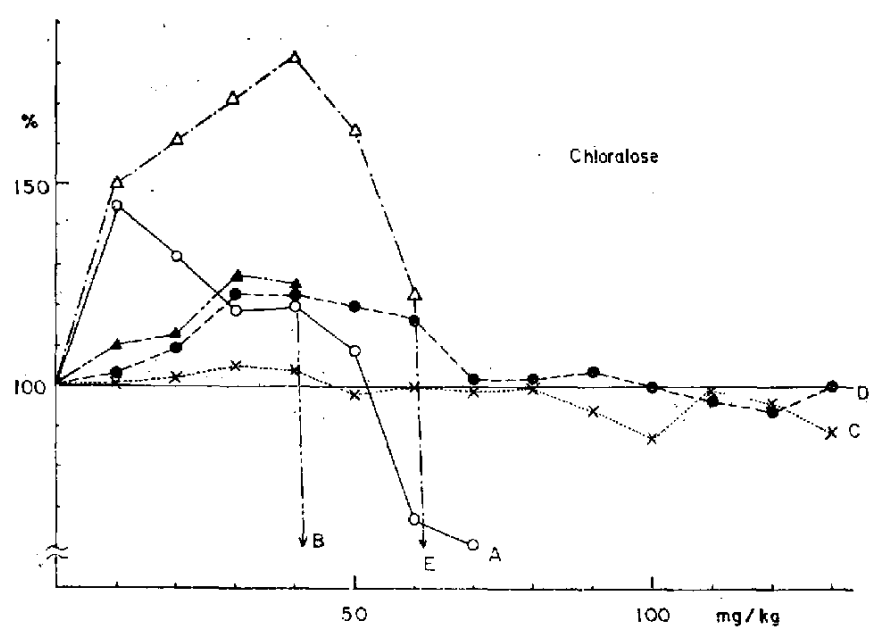

FIG. 6. Relationship between per cent changes of amplitude of the auditory cvoked potentials and infused doses of chloralose in five preparations.

the increase was observed at the total dose of 40 to $50 \mathrm{mg} / \mathrm{kg}$, at which the increase of the amplitude was about 20 to $80 \%$ of that before the infusion. Fig. 6 shows the relationship between the changes of the amplitude and infused doses in five preparations. Further continuation of the infusion turned the amplitude to an abrupt decrease far below the level before infusion in three preparations (A, B and E) manifested shock symptoms.

In the other two preparations ( $\mathrm{C}$ and $\mathrm{D}$ ) the amplitude of the potentials was in the normal range even at the total dose of $100 \mathrm{mg} / \mathrm{kg}$. The increasc of the total dose of chloralose as well as pentobarbital sodium resulted in the reduction of the duration of the evoked potentials. The decrease in the duration was 30 to $40 \mathrm{msec}$ at the dose of 20 to $30 \mathrm{mg} / \mathrm{kg}$, and $20 \mathrm{msec}$ at the dose of $80 \mathrm{to} 100 \mathrm{mg} / \mathrm{kg}$. The marked increasc in the amplitude of the potentials was charactcristic for the effect of chloralose and manifested from the total dose of 10 to $60 \mathrm{mg} / \mathrm{kg}$, as shown in Fig. 6 .

The evoked rhythmic after-discharge in the EEG of the auditory cortex was preserved apparently intact until the total dose of $50 \mathrm{mg} / \mathrm{kg}$ of chloralose, although it was depressed at the larger doses (Fig. 7). However, the after-discharge was depressed slowly but progressively in frequency, amplitude and duration along with the increase of the total dose. The rhythmic after-discharge at the dose of 10 to $20 \mathrm{mg} / \mathrm{kg}$ was $15 \mathrm{cps}$ in frequency, $200 \mu \mathrm{V}$ in amplitude and 1.0 to 1.5 seconds in duration, while at $30 \mathrm{mg} / \mathrm{kg}$ it was 8 to $10 \mathrm{cps}, 300 \mu \mathrm{V}$ and 1.5 to 2.0 seconds and further at $50 \mathrm{mg} / \mathrm{kg}$ it was 4 to 5 cps, $400 \mu \mathrm{V}$ and 2.0 seconds. With the increasc of the total dose the background patterns of the EEG showed an increase of the components of the slow waves. At the total dose of 80 to $100 \mathrm{mg} / \mathrm{kg}$ the after-discharge was deprived of its distinct configuration leaving only spike discharge, 300 to $400 \mu \mathrm{V}$ in amplitude. At the dose of 150 $\mathrm{mg} / \mathrm{kg}$ the flat background activity was accompanied with only small spike discharge. 


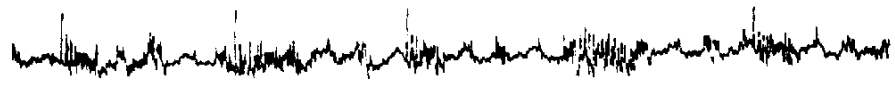

2

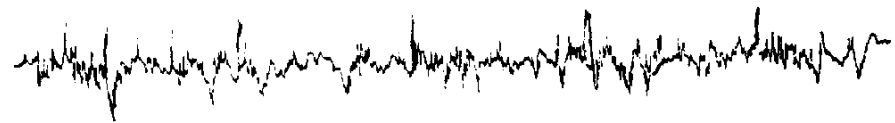

3

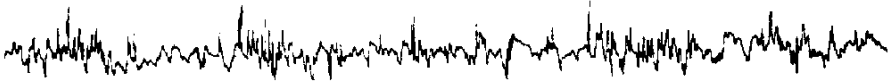

4

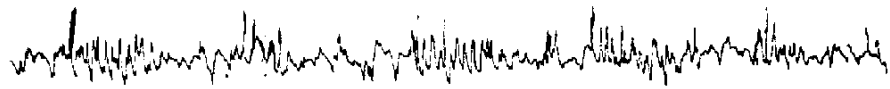

5

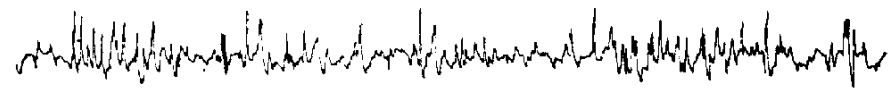

6

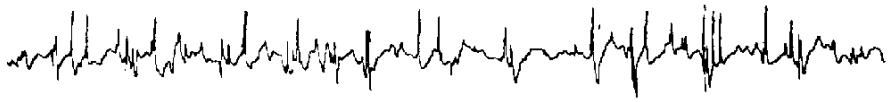

7

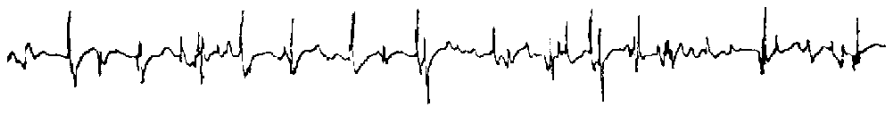

8

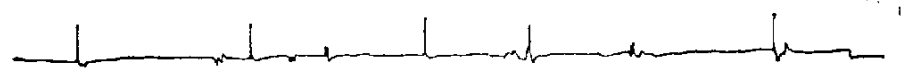

FIG. 7. Effects of infusion of chloralose on EEG recorded from MEG. (1) Before, (2) $10 \mathrm{mg} / \mathrm{kg}$, (3) $20 \mathrm{mg} / \mathrm{kg}$, (4) $30 \mathrm{mg} / \mathrm{kg}$, (5) $50 \mathrm{mg} / \mathrm{kg}$, (6) $80 \mathrm{mg} / \mathrm{kg}$, (7) $100 \mathrm{mg} / \mathrm{kg}$ and (8) $150 \mathrm{mg} / \mathrm{kg}$. Calibration : ordinate $100 \mu \mathrm{V}$, abscissa $1 \mathrm{sec}$.

Even at this dose level of chloralose the manifestation of the evoked potentials, 200 to $400 \mu \mathrm{V}$ in amplitude was still preserved. The spontaneous recovery of the effect of chloralose in the dose of 100 to $150 \mathrm{mg} / \mathrm{kg}$ was not observed within a few hours.

\section{Effects of urethane}

One animal was infused with $1.0 \mathrm{~g} / \mathrm{kg}$ of urethanc dissolved in $50 \mathrm{ml}$ Ringer's solution at the rate of 30 minutes ( $\mathrm{A}$ in Fig. 8). Other animals were infused with $0.5 \mathrm{~g} / \mathrm{kg}$ of urethane dissolved in $50 \mathrm{ml}$ of Ringer's solution at the rate of 30 minutes ( $B, C$ and $\mathrm{D}$ in Fig. 8). The amplitude of the evoked potentials decreased slowly but progressively with the increase of the total dose, and the reduction of the amplitude was about $50 \%$ at the total dose of $1.0 \mathrm{~g} / \mathrm{kg}$ of the drug. Slight increase in the amplitude of the poten- 


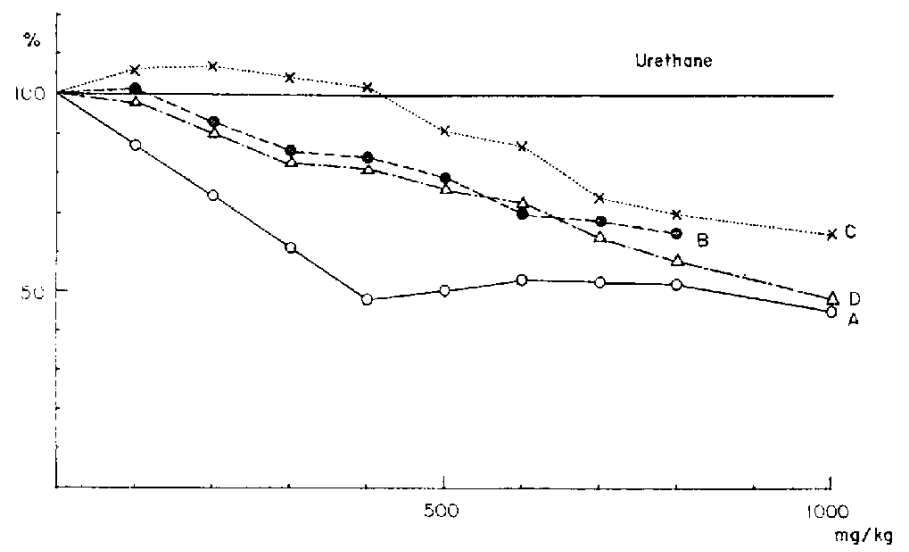

FIc. 8. Relationship between per cent changes of amplitude of the auditory evoked potentials and infused doses of urethane.

tials in the preparation $\mathrm{C}$ ( 3 to $8 \%$ ) was observed at the small dose of the drug, but this increase was within normal variation. Fig. 9 shows the depressant effect of urethane on the duration and amplitude of the potentials recorded from the auditory cortex. The duration of the potentials was decreased to $30 \mathrm{msec}$ at the total dose of 0.5 to $1.0 \mathrm{~g} / \mathrm{kg}$.

Fig. 10 illustrates the effects of infused doses of urcthane on the EEG and the evoked rhythmic after-discharge of the auditory cortex in response to click stimuli. In this figure, the evoked rhythmic after-discharge responded to every repetition of the stimulation before the infusion. The rhythmic after-discharge consisted of waves 12 to $14 \mathrm{cps}$ in frequency, $500 \mu \mathrm{V}$ in amplitude and 1.0 second in duration. The continuous infusion of urethane decreased the frcquency and amplitude and prolonged the duration of the after-discharge. - $\Lambda t$ the total dose of 0.4 to $0.6 \mathrm{~g} / \mathrm{kg}$ the after-discharge was $10 \mathrm{cps}, 300$ $\mu \mathrm{V}$ and 1.5 to 2.0 seconds, and at the dose of $1.0 \mathrm{~g} / \mathrm{kg}$ it was $8 \mathrm{cps}, 100$ to $200 \mu \mathrm{V}$ and 2.0 to 2.5 seconds. The background activity of the spontaneous EEG showed an increase of the component of the slow waves and decreased the amplitude along with the increase of the total dose.

\section{Effects of ethanol}

Ethanol was intravenously infused in the dose of $1.6 \mathrm{~g} / \mathrm{kg}$ dissolved in $100 \mathrm{ml}$ of Ringer's solution per one hour. The infusion of cthanol depressed the amplitude of the evoked potentials slowly but progressively without manifesting any increase (Fig. 11). The reduction of the amplitude about 10 to $30 \%$ was already observed at the total dose of 0.2 to $0.4 \mathrm{~g} / \mathrm{kg}$. However, further continuation of the infusion resulted in the slight progression of the reduced amplitude. The increase of the total dose of cthanol as wcll as pentobarbital sodium and chloralose caused the decrease in the duration of the potentials. The duration was $40 \mathrm{msec}$ at the dose of $0.4 \mathrm{~g} / \mathrm{kg}$ and $20 \mathrm{msec}$ at the dose of $0.8 \mathrm{~g} / \mathrm{kg}$. In addition, the infusion of the ethanol prolonged the latency to the manifestation of the potentials. Before the commencement of the infusion the latency 

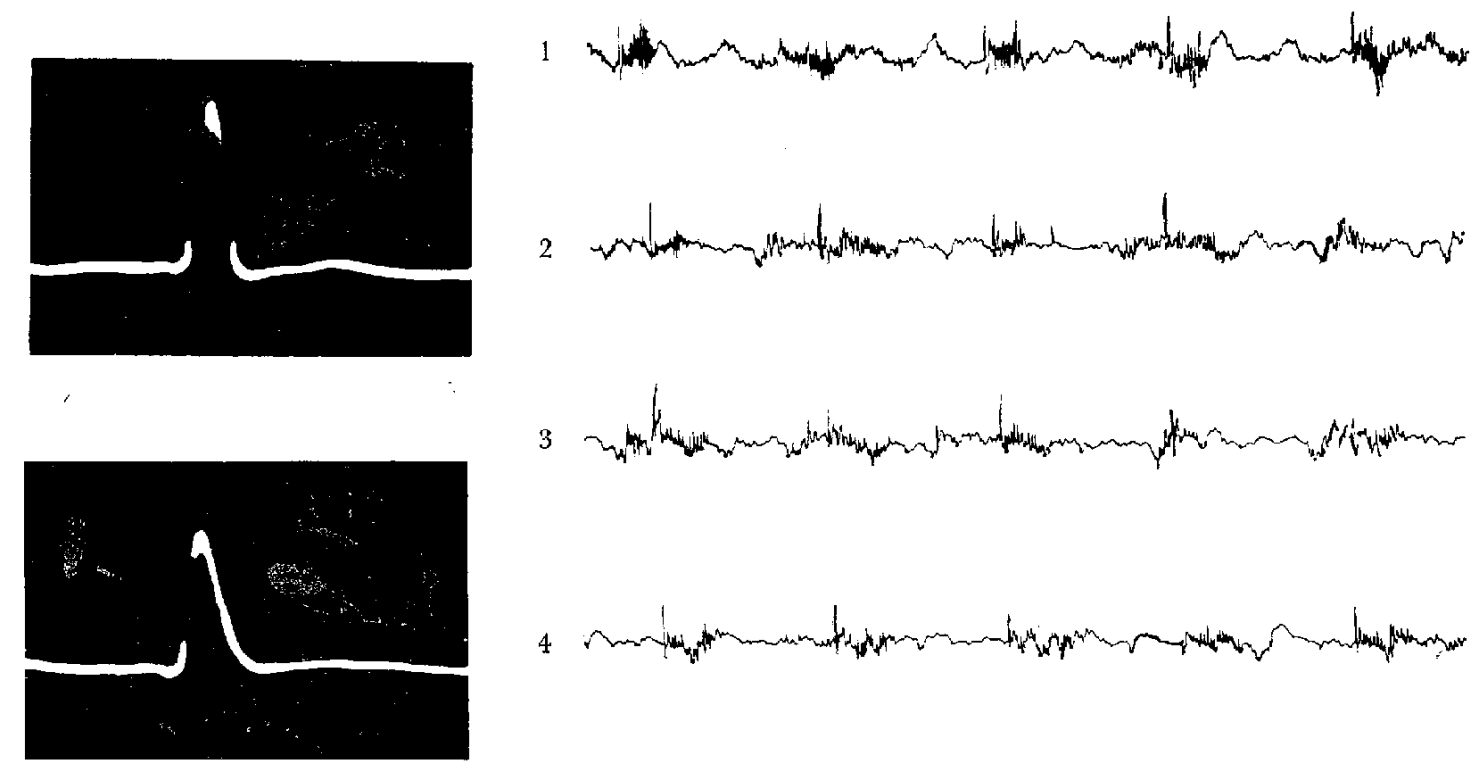

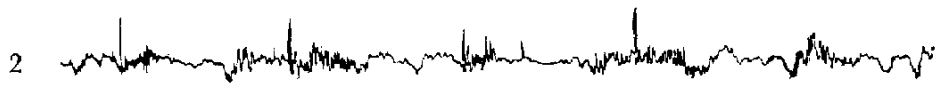

3

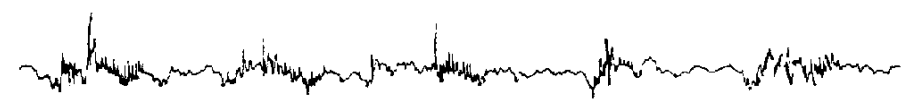

4
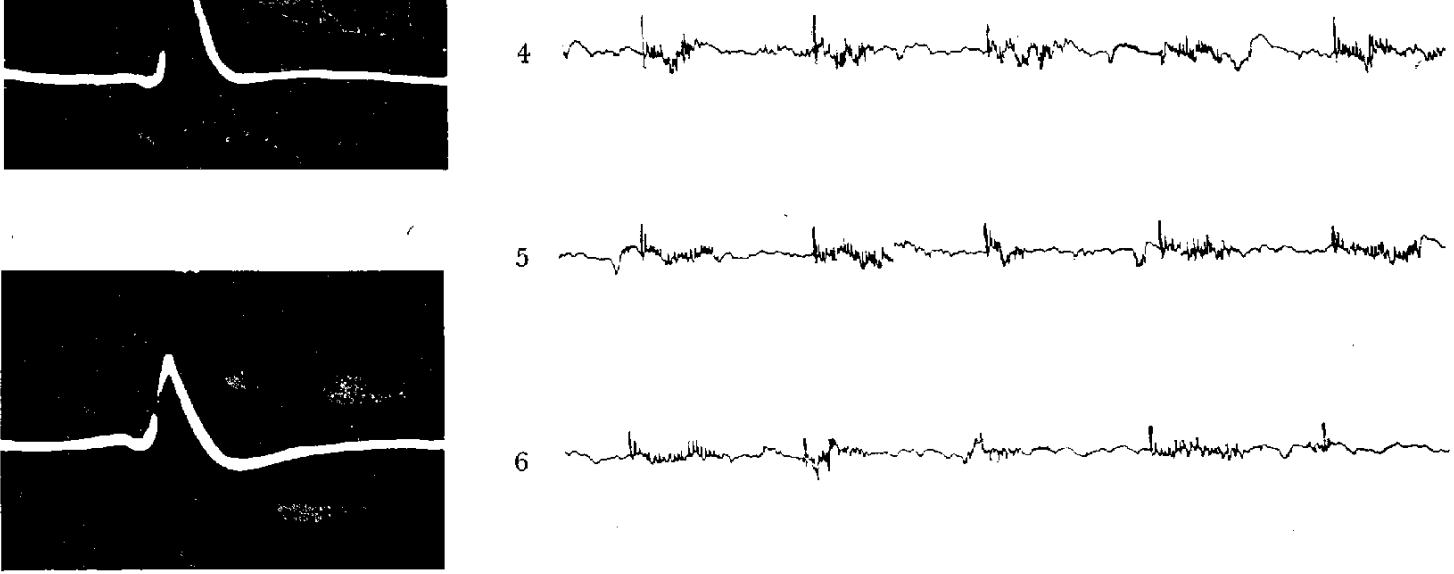

5

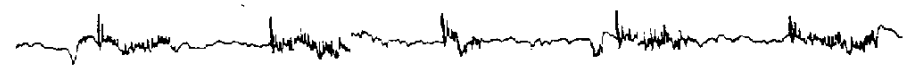

6

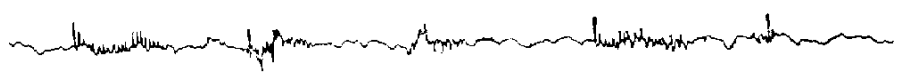

Frg. 9. Effects of infusion of urethane on the auditory evoked potentials. (1) Before, (2) 0.5 $\mathrm{g} / \mathrm{kg}$ and $(3) 1 \mathrm{~g} / \mathrm{kg}$.

Calibration: ordinate $200 \mu \mathrm{V}$, abscissa $20 \mathrm{msec}$.

FIs. 10. Effects of infusion of urethane on EEG recorded from MEG.

(1) Before, (2) $0.1 \mathrm{~g} / \mathrm{kg}$, (3) $0.2 \mathrm{~g} / \mathrm{kg}$, (4) $0.4 \mathrm{~g} / \mathrm{kg}$, (5) $0.6 \mathrm{~g} / \mathrm{kg}$, (6) $0.8 \mathrm{~g} / \mathrm{kg}$ and (7) $1.0 \mathrm{~g} / \mathrm{kg}$.

Calibration : ordinate $100 \mu \mathrm{V}$, abscissa 1 sec.

was 9.0 to $9.1 \mathrm{mscc}$, but it was prolonged to 10.5 to $10.6 \mathrm{msec}$ at the total dose of 0.8 $\mathrm{g} / \mathrm{kg}$ of ethanol.

Though the evoked rhythmic after-discharge in response to click stimuli was little affected at the initial phase of the infusion, it was significantly depressed in the frequency and prolonged in duration from the dose of above $0.4 \mathrm{~g} / \mathrm{kg}$. Moreover, the afterdischarge was not always observed to respond to every click stimuli, as shown in Fig. 12. At the level of $0.8 \mathrm{~g} / \mathrm{kg}$, the distinct calibration of the after-discharge was difficult because of the marked intermingling of the spindle waves in the spontaneous EEG. 


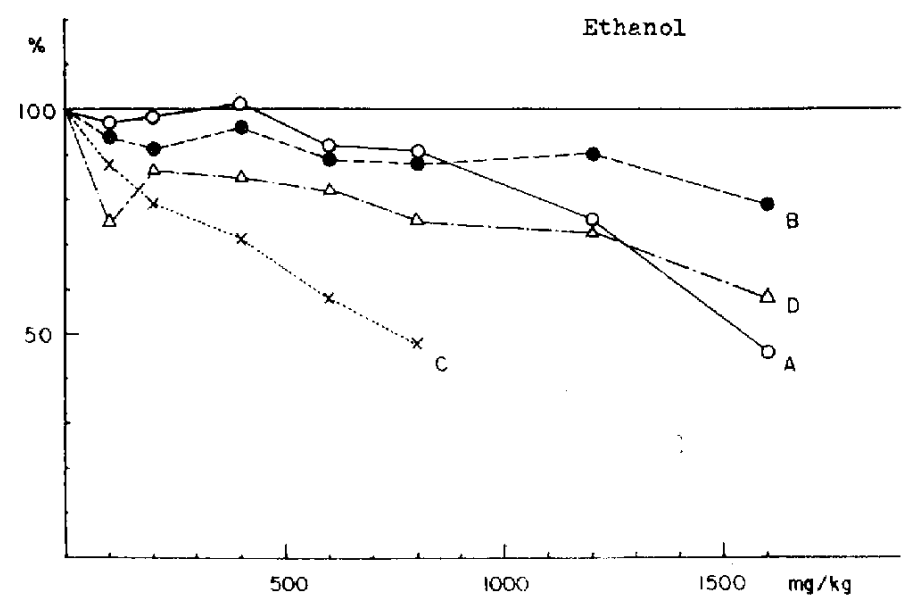

Fir: 11. Relationship between per cent changes of amplitude of the auditory evoked polentials and infused doses of ethanol in four preparations.

\section{Liffects of chlorproma-ine}

Chlorpromazine was intravenously infused at the dosf of $20 \mathrm{mg} / \mathrm{kg}$ dissolved in 100 $\mathrm{ml}$ of physiological saline solution per one hour. Being somewhat different from other central depressants, the infusion of chlorpromazine increased the amplitude of the cvoked potentials immediately after the commencement of injection, as shown in Fig. 13 . The peak effect of the increase (20 to $40^{\circ}$ ) ) was observed at the total dose of 4 to $8 \mathrm{mg} / \mathrm{kg}$. However, above $10 \mathrm{mg} / \mathrm{kg}$ the amplitude of the potentials tended to decline. But the amplitude at the total dose of 10 to $18 \mathrm{mg} / \mathrm{kg}$ of the drug was still higher than that before the infusion. The further increase of the total dose caused the decrease of the amplitude, but the decrease at the dose of $20 \mathrm{mg} / \mathrm{kg}$ was only 10 to $20 \%$. Furthermore, chlorpromazine scarcely resulted in the decrease of the duration of the potentials.

The infusion of chlorpromazine caused gradually and progressively the manifestation of the slow waves in the spontaneous E.EG of the auditory cortex along with the increase of the total dose (Fig. 14). The spontaneous EEG at the dose of $16 \mathrm{mg} / \mathrm{kg}$ showed the pattern of slow waves, 5 to 8 cps in frequency.' 'The rhythic after-discharge was evoked by every repetition of click stimuli until the total dose of $6 \mathrm{mg} / \mathrm{kg}$. Above 10 $m g / \mathrm{kg}$ of chlorpromazine, the auditory cortex often. failed to respond with evoked rhythmic after-dischargc. However, even in the total dose of $20 \mathrm{mg} / \mathrm{kg}$ the after-discharge, 7 to $8 \mathrm{cps}$ in frequency, 100 to $200 \mathrm{\mu V}$ in amplitude and 2.0 seconds in duration was occasionally observed.

\section{Effecls of morftine}

The effects of morphine on the cvoked potentials and the rhythmic after-discharge recorded from the auditory cortex were studied in 4 anesthctized (pentobarbital sodium, intraperitoneally) and 3 unanesthetized cats. In one anesthetized animal, the intravenous injection of $6 \mathrm{mg} / \mathrm{kg}$ of morphine resulted in the prompt depression of the amplitude 
1

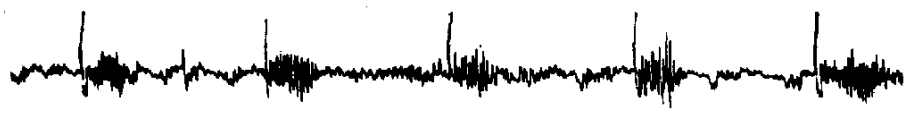

2

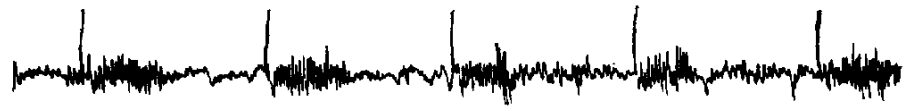

3

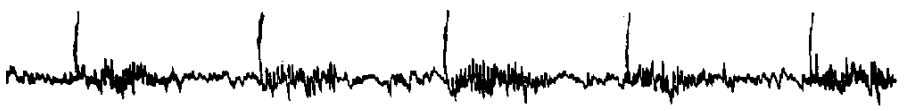

4

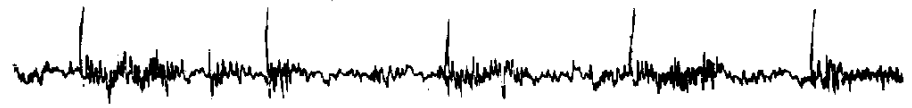

5

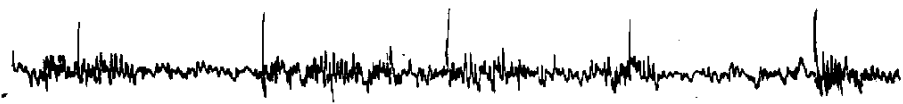

6

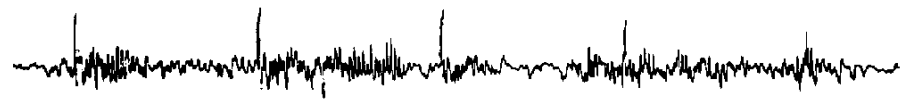

7

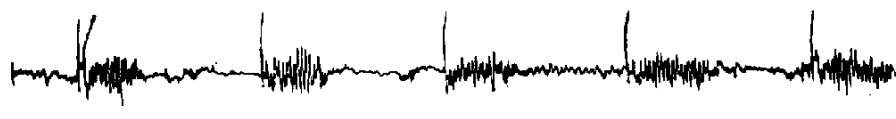

Fis. 12. Fiffects of infusion of ethanol on $\mathrm{EEG}$ recorded from MEG. (1) Before, (2) $0.1 \mathrm{~g} / \mathrm{kg}$, (3) $0.2 \mathrm{~g} / \mathrm{kg}$, (4) $0.4 \mathrm{~g} / \mathrm{kg}$, (5) $0.8 \mathrm{~g} / \mathrm{kg},(6) 1.2 \mathrm{~g} / \mathrm{kg}$ and (7) $1.6 \mathrm{~g} / \mathrm{kg}$.

Calibration : ordinate $100 \mu \mathrm{V}$, abscissa $1 \mathrm{sec}$.

of the cvoked potentials and the complete abolition of the potential within 10 minutes. The full recovery was observed at least 30 minutes after the disappearance of the potential. However, in the other threc anesthetized preparaions maintained by the artificial respiration, the same dose of morphine did not affected the cvoked potential. Therefore, the depressant effects of morphine on the cvoked potential in one preparation withoul artificial respiration were likely to derive from the oxygen deprivation of the cortex produced by the depression of the respiratory center. The intravenous infusion of morphine at the rate of $20 \mathrm{mg} / \mathrm{kg}$ dissolved in $50 \mathrm{ml}$ of Ringer's solution 


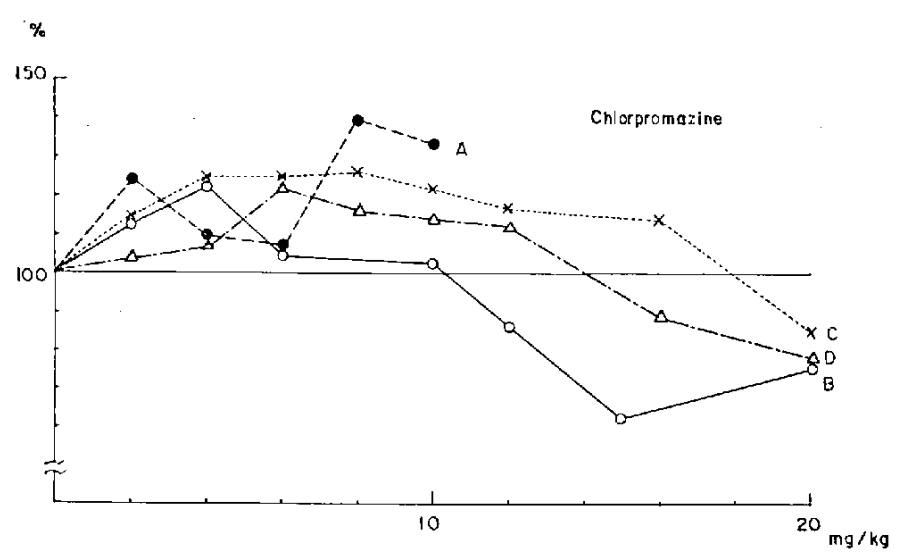

FIG, 13. Relationship between per cent changes of amplitude of the auditory evoked potentials and infused doses of chlorpromazine.

per 30 minutes did not affect the evoked potential in latency, amplitude or duration in the unanesthetized animals.

\section{Effects of the intravenous infusion of central stimulants}

\section{Effects of methamphetamine}

One milligram per kilogram of the methamphetamine dissolved in $50 \mathrm{ml}$ of Ringer's solution was intravenously infused in 30 minutes. However, consistent tendency of the effects of methamphetamine on the evoked potential was not found because of much individual variation of the response. The amplitude of the potentials in some preparations showed an increase during and after the infusion. The highest incrcase was about $40 \%$. In other preparations the infusion of methamphetamine decreased the amplitude and maximal decrease was about 20 to $30 \%$. Accompanied with the manifestation of low voltage and fast waves, the evoked rhythmic after-discharge consisted of 3 to 4 spikes was shortened in duration immediately after the commencement of the infusion. At the dose of 0.8 to $1.0 \mathrm{mg} / \mathrm{kg}$ the after-discharge disappeared totally.

\section{Effects of strychnine}

One hundred microgram per kilogram of strychnine dissolved in $100 \mathrm{ml}$ of Ringcr's solution was infused at the rate of one hour. In one of the preparations the infusion of strychnine reduced the amplitude of the evoked potentials. The rate of reduction was about $30 \%$ at the total dose of $30 \mu \mathrm{g} / \mathrm{kg}$. However, further infusion of strychnine did not promote the reduction. On the other hand, the other preparations showed an increase of the amplitude of the potentials on response to infusion of strychnine. The rate of increase was about $60 \%$ at the dose of $30 \mu \mathrm{g} / \mathrm{kg}$. The infusion of strychnine resulted in the increase manifestation of the fast waves in the spontaneous EEG of the auditory cortex, accompanied with irregularities in the evoked rhythmic after-discharge. The spike waves were occasionally observed above the total dose of $50 \mu \mathrm{g} / \mathrm{kg}$ of strychnine. 


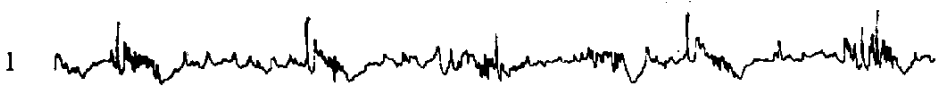

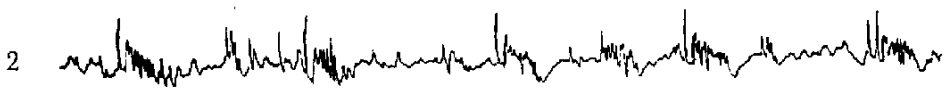

3

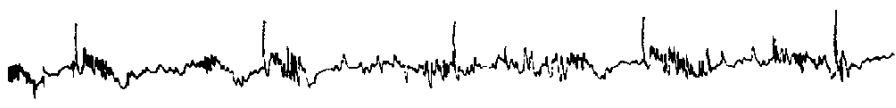

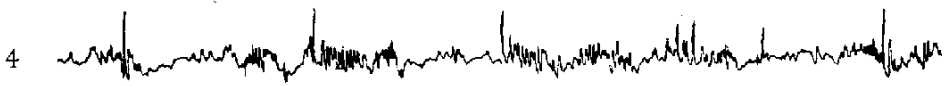

5

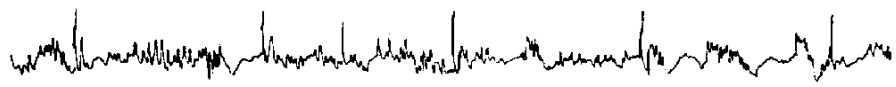

6

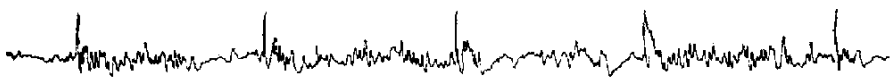

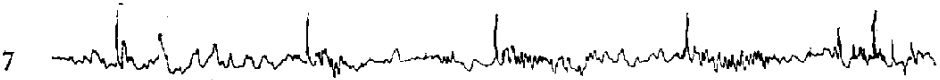

8
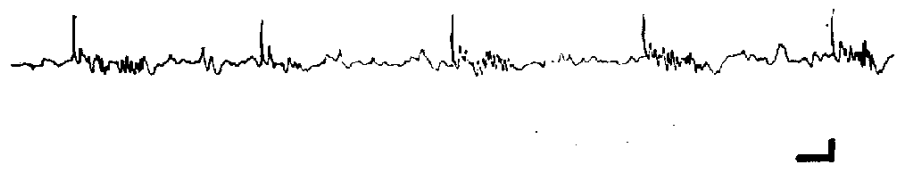

FiG. 14. Effects of infusion of chlorpromazine on EEG from MEG.

(1) Before, (2) $2 \mathrm{mg} / \mathrm{kg}$, (3) $4 \mathrm{mg} / \mathrm{kg},(4) 6 \mathrm{mg} / \mathrm{kg}$, (5) $10 \mathrm{mg} / \mathrm{kg}$,

(6) $12 \mathrm{mg} / \mathrm{kg}$, (7) $16 \mathrm{mg} / \mathrm{kg}$ and $(8 ; 20 \mathrm{mg} / \mathrm{kg}$.

Calibration : ordinate $100 \mu \mathrm{V}$, abscissa 1 sec.

\section{DISCUSSION}

The distribution of the auditory cortex in the primary auditory area (AI), the secondary auditory area (AII) and posterior ectosylvian area in the cat shown by Kornmüller (9) and Mickle and Ades (10) was confirmed in the present experiments by recording the evoked potentials on the auditory cortex in response to repetition of the click stimuli. Though the evoked potentials in the unanesthetized animals were easily affected by environmental conditions, they were repeatedly observed in response to clicks delivered at the interval of 1 to 2 seconds in the semi-sound-proof dark room. In the intact cat ancsthetized with the intraperitoneal injection of pentobarbital sodium, the 
evoked potentials were recorded in the considerably wide areas of the cortex including AEG, MEG, PEG, ASG and MSG. The highest amplitude of the potential (50 to 200 $\mu \mathrm{V}$ ) was observed in the central portion of the MEG.

In the unanesthetized encéphale isolé preparations, the magnitude and distribution of the evoked potentials in response to the click stimuli differed from those in the anesthetized intact cats in the following points: 1) The potentials were mainly recorded in the MEG. 2) The amplitude of the potential was higher and the duration was longerlasting than those in the anesthetized intact animals. The evoked potential with highest amplitude was observed in the relatively narrow portion of the MEG (the limited area of $\mathrm{AI}$ ), and the slight deviation of the recording electrode to AII or posterior ectosylvian area resulted in the progressive reduction of the amplitude. The results in the present experiments agree well with the conclusions shown by Reinberger and Jasper (5) that the evoked potential in the unanesthetized cat is higher in amplitude and longer in duration than that in the anesthetized intact cat. 3) However, the evoked potential in the encephale isole preparation was easily susceptible to the changes of the environmental condition. It was often observed that immediately after the manifestation of the evokcd potential with the extremely high amplitude the auditory cortex showed refractoriness to succeding stimuli. Such refractoriness of the auditory cortex is considered to be brought about by the change of the environmental conditions or by other factors probably related with the level of consciousness in the animal. The external stimuli such as noise, light or touch depressed the evoked potential markedly.

The spontaneous EEG in the motor cortex of the unanesthetized but restrained cat showed a background activity consisted of low voltage fast waves $(20$ to $30 \mathrm{cps}$ and 20 to $60 \mu \mathrm{V}$ ) intermingled with the spindle bursts ( 8 to $12 \mathrm{cps}$ and 200 to $300 \mu \mathrm{V}$ ). The spontaneous electrical activity recorded from the auditory cortcx showed the similar pattern. The evoked rhythmic after-discharge of the waves, 10 to $15 \mathrm{cps}$ in the frequency, 200 to $300 \mu \mathrm{V}$ in amplitude and $1 \mathrm{sec}$ in duration was superimposed in the EEG of the auditory cortex immediately after the evoked potentials induced with click stimuli. The manifestation of the evoked rhythmic after-discharge was also affected by the environmental conditions. The evoked rhythmic after-discharge in the EEG of the auditory cortex differed from spindle bursts of the motor cortex. The evoked rhythmic after-discharge followed the external acoustic stimuli was more in frequency and shorter in duration than the spindle bursts. The evoked repetitive discharge in the auditory EEG was shown to originate from the cerebral cortex and the subcortical nuclei by Morison and Dempsey (11) and Kristinnsen and Courtois (12) or from the reverberating circuits between the cerebral cortex and the subcortical relay nuclei by Verzeano et al. (13). The spindle bursts recorded from auditory cortex induccd by the click stimuli or by single shock on the auditory cortex or medial geniculate body have been shown by Kawamura and Yamamoto (14). They have reported that these spindle bursts did not relate with spindle bursts in the sensory-motor cortcx induced by the single shock on the caudate nucleus. Summarizing the mode of the activation of the auditory EEG, 
Chang (15) has referred to the evidence that the presence of the evoked periodic discharge is dependent upon the integrity of the pathways between the cerebral cortex and the thalamic nucleus concerned. But he has excluded the possibility that all kinds of rhythmic discharges can be regarded as the activity of reverberating circuits. Further, he has referred to the possibility that the activity of the corticothalamic reverberating circuit does not reflect directly on the simple circulating conduction of the acoustic impulse which pass through the neurons in the closed chain, though the specific periodic after-discharge is some indication for the mode of the reverberating circuits between the sensory cortex and thalamus. The evidence that the cortical neurons activated by the afferent impulse bchaved differently from the spontaneous activity of the acoustic EEG has been shown by Burns (16). The exact mode of the interaction between the evoked rhythmic after-discharge in the auditory cortex in response to click stimuli and the auditory sensation remains to be settled.

Little was known about the cffects of the anesthetics or the level of the anesthesia on the activity of the central auditory structures. The effects of the continuous infusion of the anesthetics dissolved in the Ringer's solution or physiological saline solution on the evoked potential and the evoked rhythmic after-discharge recorded from the auditory cortex were observed in the present experiments. By use of the continuous infusion of the anesthetics including pentobarbital sodium, chloralose, urethane, ethanol, chlorpromazine and morphine the correlation between the doses and the effects of the drugs on the evoked potential and the evoked rhythmic aftcr-discharge was easily investigated.

TABLE 1. Effects of depressants on the evoked potential and rhythmic after-discharge in the auditory cortex.

\begin{tabular}{|c|c|c|c|c|c|c|c|}
\hline \multirow{2}{*}{ Drugs } & \multirow{2}{*}{ Doses } & \multicolumn{2}{|c|}{ Evoked potential } & \multicolumn{4}{|c|}{ Rhythmic after-discharge } \\
\hline & & Amplitude & Duration & $\begin{array}{l}\text { Rate of } \\
\text { occurrence }\end{array}$ & Amplitude & Frequency & Duration \\
\hline \multirow{2}{*}{ Pentobarb. sod. } & Small dose & $\uparrow$ & no change & $\uparrow$ & no change & no change & $\uparrow$ \\
\hline & Large dose & $\downarrow \downarrow$ & $\downarrow \downarrow$ & $\begin{array}{c}\downarrow \text { or } \\
\text { disappear }\end{array}$ & $\downarrow$ & $\downarrow$ & $\uparrow$ \\
\hline \multirow{2}{*}{ Chloralose } & Small dose & $\uparrow \uparrow$ & $\begin{array}{c}\text { no change } \\
\text { or } 1\end{array}$ & no change & $\uparrow$ & no change & $\uparrow$ \\
\hline & Large dose & $\downarrow$ & $\downarrow \downarrow$ & $\begin{array}{c}\downarrow \downarrow \text { or } \\
\text { disappear }\end{array}$ & $\downarrow$ & $\downarrow \downarrow$ & \\
\hline \multirow{2}{*}{ Urethane } & Small dosc & $\downarrow$ & $\downarrow$ & no change & no change & no change & $\uparrow$ \\
\hline & Large dose & $\downarrow \downarrow$ & $\downarrow$ & $\downarrow$ & $\downarrow$ & $\downarrow$ & $\uparrow$ \\
\hline \multirow{2}{*}{ Ethanol } & Small dose & $\downarrow$ & $\downarrow$ & $\uparrow$ & no change & no change & $\uparrow$ \\
\hline & Large dose & $\downarrow$ & $\downarrow$ & $\begin{array}{c}\text { no change } \\
\text { or } \downarrow\end{array}$ & $\downarrow$ & $\downarrow$ & $\uparrow$ \\
\hline \multirow{2}{*}{ Chlorpromazine } & Small dose & $\uparrow \uparrow$ & no change & $\uparrow$ & $\uparrow$ & no change & no change \\
\hline & Large dose & $\downarrow$ & $\downarrow$ & no change & no change & $\downarrow$ & $\uparrow$ \\
\hline Morphine & Large dose & no change & no change & & & & \\
\hline
\end{tabular}

$\uparrow$ : Slight increase $\downarrow$ : Slight decrcase

$\uparrow \uparrow:$ Marked increase $\downarrow \downarrow$ : Marked decrease 
The evoked potential was variably affected by the doses of the appropriate anesthetics. The conspicuous findings in the experiments have been that the relatively smaller doses of pentobarbital sodium, chloralose and chlorpromazine increased the amplitude of the evoked potential, while the small as well as large doses of urethane and ethanol reduced the amplitude. The duration of the evoked potential was markedly dccreased by the depressants exccpt chlorpromazine as shown in Table 1. The increase of the amplitude by pentobarbital sodium was 10 to $40 \%$ in the doses from 2 to $5 \mathrm{mg} / \mathrm{kg}$. Thereafter, the amplitude was gradually and progressively depressed in response to the further increasc of the dose, and at the dose level of $20 \mathrm{mg} / \mathrm{kg}$ the amplitude decreased by 30 to $50 \%$. Concomitant with the changes of the amplitude, the duration of the evoked potential decreased from $50 \mathrm{msec}$ to 30 to $40 \mathrm{msec}$ in the dose level of $10 \mathrm{mg} / \mathrm{kg}$ and 20 to $30 \mathrm{msec}$ in dose level of $20 \mathrm{mg} / \mathrm{kg}$. The dose levcl of 20 to $40 \mathrm{mg} / \mathrm{kg}$ of chloralose resulted in the increase of the amplitude about 20 to $80 \%$, but the further increase of the dose resulted in the progressive reduction of the amplitude. The infusion of the chloralose caused the decrease in the duration of the evoked potential, 30 to $40 \mathrm{msec}$ in the dose of 20 to $30 \mathrm{mg} / \mathrm{kg}$ and $20 \mathrm{msec}$ in the dose of 80 to $100 \mathrm{mg} / \mathrm{kg}$. The marked increase in the amplitude was observed by chlorpromazine. The increase in the amplitude at the dose of 4 to $8 \mathrm{mg} / \mathrm{kg}$ of chlorpromazine was 20 to $40 \%$, and the further increase of the dose resulted in the slight decrease in the amplitude. The duration of the evoked potential was slightly shortened by the doses of chlorpromazine. The amplitude of the evoked potential progressively reduced immediately after the infusion of urethane or ethanol. The reduction of the amplitude at the dose level of $1.0 \mathrm{~g} / \mathrm{kg}$ of urethane was about $50 \%$, and the duration of the response was also decreased. The decrease in the amplitude was 10 to $30 \%$ at the dose of 0.2 to $0.4 \mathrm{~g} / \mathrm{kg}$ of ethanol. However, the spontaneous activity of the auditory cortex consisted of the low voltage fast wave, 20 to $60 \mu \mathrm{V}$ in amplitude and 30 to $35 \mathrm{cps}$ in frequency or the slow waves, 15 to $20 \mathrm{cps}$ in frequency.

In response to click stimuli the cvoked potential was followed by the rhythmic after-discharge on the auditory cortex. Though the evoked rhythmic after-discharge manifested not always in response to every stimulus delivered at the time-interval of 5 seconds, the infusion of small doses of the depressants accelerated the manifestation of the discharge responding to every click stimulus. The accelerating effect was clearly shown by the infusion of pentobarbital sodium, chlorpromazine and ethanol. However, further infusion of the depressants resulted in the slowing of background activity of the EEG in the auditory cortex accompanied with the depression of corresponding manifestation of the evoked rhythmic after-discharge. In addition, the evoked rhythmic afterdischarge was decreased in frequency and prolonged in duration. Above the dose level of $20 \mathrm{mg} / \mathrm{kg}$ of pentobarbital and $80 \mathrm{mg} / \mathrm{kg}$ of chloralose the evoked rhythmic afterdischarge disappeared totally, while the depressed rhythmic after-discharge was still observed at the dose level of $1.0 \mathrm{~g} / \mathrm{kg}$ of urethane or $0.8 \mathrm{~g} / \mathrm{kg}$ of ethanol. Though the larger dose $(20 \mathrm{mg} / \mathrm{kg})$ of chlorpromazine produced the marked slowing of the back- 
ground activity in the auditory cortex, the manifestation of the evoked rhythmic afterdischarge was scarcely affected. The reduction of the frequency and the prolongation of the duration were also observed in the large doses of chlorpromazine.

The mode of action of the ascending reticular activating system on the arousal state and the concentration of attention has been investigated by Magoun (17), Moruzzi et al. (18) and Jasper (19). They have shown that the electrical activity in the cortical EEG attributable to the arousal state was derived from the direct stimulation of the brain stem reticular formation. They have concluded that the system activates the cortical function of the brain. The diffuse thalamocortical projection system, the fiber groups from the unspecific thalamic nuclei to the cercbral cortex was reported by Jasper (19) to activate the level of the consciousness. The effects of the central depressants on the arousal responses to stimulation of the brain stem reticular formation and on the recruiting responses to stimulation of the unspecific thalamic nuclei have been studies by many investigators including Domino (20) and King (2I). They reported that the small doses of the barbiturates depressed the reticular arousal but enhanced the recruiting response, and that the recruiting response was enhanced by the small dose but depressed by large dose of chloralose, while the arousal response was depressed by the anesthetic doses. The depressant effect of chlorpromazine on the arousal response was also reported (22, 23). Jasper and others suggested that the enhancement of the recruiting response by small doses of the depressants derived from the release phenomenon induced by the depression of the arousal response and that the manifestation of the spindlc waves was activated rather from the dircet of the drugs on the diffuse thalamocortical projection system. In the present experiments, the marked increase in the amplitude of the evoked potential at the small dose level of pentobarbital sodium, chloralose and chlorpromazine is likely to derive from the facilitation of the acoustic stimuli through the auditory pathway caused by the depression of the reticular formation. The regular manifestation of the evoked rhythmic after-discharge at the small dose level of the depressants is also likcly to derive from the release phenomenon in the corticothalamic reverberating circuit caused by the depression of the reticular formation. The larger dose of the depressants is likely to result in the reduction in the amplitude of the evoked potential and the depression of the regular manifestation of the evoked rhythmic after-discharge by virtuc of the direct depressant effect of drugs on the ascending auditory pathway and the auditory cortex.

Urethane and ethanol differed from pentobarbital sodium, chloralose and chlorpromazine in that former drugs reduced the amplitude of the cvoked potential even in small dose lcvel. Especially, urethane gradually depressed the activity of the cerebral cortex as wcll as the subcortical regions with an increase of the dose level. The lack of the facilitatory effects of the drugs requires further investigation.

Variable effects were obscrved by the infusion of methamphetamine and strychnine on the evoked potential of the auditory cortcx. The administration of methamphetamine reduced the amplitude in three cats and increased it in two cats. Immediately after 
the commencement of the infusion of methamphetamine the evoked rhythmic afterdischarge disappeared totally in association with the marked arousal waves of the spontancous EEG on the auditory cortex. Studing the effects of the methamphetamine on the brain stem reticular formation and the diffuse thalamocortical projection system in the rabbits, Kikuchi (24) has concluded that the arousal waves in the cortical EEG derives from the activation of the reticular formation by which the recruiting response was also depressed.

\section{SUMMARY}

The effects of the infusion of the various anesthetics on the evoked potentials and the evoked rhythmic after-discharges on the auditory cortex in response to the click stimuli were investigated in the encéphale isolé preparations of unanesthetizcd cats.

1. The croked potential was mainly rccorded in the narrow area of the middle ectosylvian gyrus, and was easily and sensitively affected by the change of the environmental conditions and the slight dislocation of the recording electrode on the cortex. The procedures resulted usually in the progressive reduction of the amplitude. The evoked potential in the unanesthetized cat was higher in amplitude and shorter in duration than that in the anesthetized cat.

2. The manifestation of the evoked potential in response to maximal click stimuli was followed by the evoked rhythmic after-discharge, 10 to $15 \mathrm{cps}$ in frequency, 200 to $300 \mu \mathrm{V}$ in amplitude and lasting for about 1.5 seconds. The evoked rhythmic afterdischarge in the auditory cortex did not synchronize with the spontaneous spindle bursts in the motor cortex.

3. The infusion of the relatively small doses of pentobarbital sodium, chloralose and chlorpromazine increased the amplitude of the evoked potential, while the infusion of urethane and ethanol even in the small doses reduced the amplitude. The duration of the evoked potential was markedly decreased by the depressants except chlorpromazine. The infusion of pentobarbital sodium, chloralose and ethanol in the small dose accelerated the manifestation of the evoked rhythmic after-discharge to every click stimulus.

4. The infusion of the depressants in larger doses depressed markedly the amplitude of the cvoked potential, reduced the evoked rhythmic after-discharge in frequency and prolonged the rhythmic after-discharge in duration. Above the dose level of 20 $\mathrm{mg} / \mathrm{kg}$ of pentobarbital sodium and $80 \mathrm{mg} / \mathrm{kg}$ of chloralose the evoked rhythmic afterdischarge disappeared totally, while the depressed rhythmic after-discharge was still observed at the dose level of $1.0 \mathrm{~g} / \mathrm{kg}$ of urethane, $800 \mathrm{mg} / \mathrm{kg}$ of ethanol and $20 \mathrm{mg} / \mathrm{kg}$ of chlorpromazine. Twenty milligram per kilogram of morphine did not affect the evoked potential and the evoked rhythmic after-discharge.

5. The effects of $1.0 \mathrm{mg} / \mathrm{kg}$ of methamphetamine and $100 \mu \mathrm{g} / \mathrm{kg}$ of strychnine on the evoked potential and evoked rhythmic after-discharge on the auditory cortex were not found the consistent tendencies because of much individual variation of the response. 
Acknowledgement: The author wishes to express his appreciation to Assistant Professor S. Takaori of Department of Pharmacology, Faculty of Medicine, Kyoto University, for his kind guidance and helpful suggestions on the study, and for the criticism in the preparation of the manuscript.

\section{REFERENCES}

1) RaAB, D.H. AND Aues, H.W. : J. Neurophysiol. 12, $101(1949$

2) NepF, W.D., Fisher, J.F., DiamonN, I.T. AND YFI.A, M. : Bid. 19, 500 (1956)

3) Litly, J.C. : Amer. I. Hhysiol. 176, 493 (1954)

4 Lilly, J.C. AND Cherry, R.B. : J. Neurophysiol. 17, 52! 1954

5) Reinherger, M.B. and Jaspeir, H.H. : Amer. J. Physinl. 119, 186 1939

6! Brazifr, M.A. : Brit. J. Anesth. 33, 194 (1961)

7) KIANG, N.Y., MEame, J.H. AND GI.ARK, L.F. : Science 133, 1927 1961)

8) Pradian, S.N. And Galambos, R. :J. Pharmacol. 139, 97 (1963)

9. Kornmüllifir, A.E. : Handbook of Physiology, Section 1, Neurophysiology 1, edited by FiEL.d, J., p. 591, Amer. Physiol. Society, Washington (1959)

10) Micki.f, W.A. And Adlis, H. W. : J. Neurophysiol. 16, 603 (1953

11 Morison, R.S. And Demisey, E.W. : Amer.J. Physiol. 135, 281 1942

12) Kristinnsien, K. And Courtois, G. : Electroenceph. din. Neurophysiol. 1, 265 :1919;

13) Vertiano, M., Lindsiey, D.B. and Magoun, H. W. : J. Neurophysiol. 16, 181 1953.

14) Kawamura, H. ann Yamamoto, K. : Jap. J. Physiol. 11, 260 1951

15: Chang, H.T. : Handbook of Physiolugy, Section 1, Neurophysiology 1, edited by Fra..D, J., p. 292, Amer. Physiol. Society, Washington 1959

16) Burns, D.B. : J. Physiol. 127, 168 (1955)

17) Magoun, H.W. : Physiol. Rev. 30, 495 1950

18 Morruzzi, G. and Magoun, H.W. : Electroenceph. clin. Neurophysiol. 1, 455 (1949)

19) JASPER, H.H. : Ibid. 1, 405 (1949)

20) Domino, E.F. : J. Pharmacol. 115, 4491955

21) Kivg, E.E. : Ibid. 116, 407 (1956)

22) TAKAORI, S. : Folia pharmacol. japon. 54, 7 (1958)

23. Takagt, H., Yamamóto, S. and Takaori, S. : Hid. 54, 113 1958

24) КіkUCH, T. : lbid. 57, 173 1961 